\title{
Organization Overviews and Role Management: Inspiration for Future Desktop Environments
}

\author{
Catherine Plaisant and Ben Shneiderman* \\ Human-Computer Interaction Laboratory \\ Center for Automation Research \\ *also Department of Computer Science \& \\ Institute for Systems Research \\ University of Maryland, College Park, MD 20742 \\ Tel. (301) 405-2768 and 2680 \\ plaisant@cs.umd.edu,ben@cs.umd.edu
}

\begin{abstract}
In our exploration of future work environments for the World Bank we proposed two concepts. First, organization overviews provide a consistent support to present the results of a variety of manual or semi-automated searches. Second, this view can be adapted or expanded for each class of users to finally map the multiple personal roles an individual has in an organization. After command line interfaces, graphical user interfaces, and the current "docu-centric" designs, a natural direction is towards a role-centered approach where we believe the emphasis is on the management of those multiple roles. Large visual overviews of the organization can be rapidly manipulated and zoomed in on to reveal the multiple roles each individual plays. Each role involves coordination with groups of people and accomplishment of tasks within a schedule.
\end{abstract}

\section{Introduction}

We worked with the World Bank, a large international organization, to explore desktop environments of the near future[1]. We focused on a subset of problems that employees regularly struggle with: finding people who can help, searching documents and resources, and juggling many roles within the organization. A low-fidelity prototype was developed to illustrate several concepts which we believe provide some answers to those difficult problems and which we hope will inspire the development of future desktop environments. Our prototype was developed with Macromedia Director using a 21 inch monitor (1152x870 resolution). A video demonstrating the prototype is available[2].

\section{Selecting a subset of common problems}

Before selecting a focus for our study we learned about the Bank's organization, their project life-cycle, document management, email practices, training and availability of specialized tools (e.g. for statistics or economics analysis). Fifteen employees were interviewed and we had hands-on experience with the systems being used and with the proto- types of the newer systems being prepared. We identified three problems that Bank employees regularly struggle with, and which are also significant problems outside the Bank:

(1) Finding people who can help in the organization (sector experts, software tools experts, natives of a country etc.) Current directories are clumsy to use, do not facilitate browsing and are disconnected from other useful databases (e.g. directories are usually not connected to report databases).

(2) Searching for documents and resources within the organization. The bank offers a large number of tools to find documents and resources but their existence is not widely known, and each requires learning a new user interface.

(3)Juggling many roles within the organization. Managers can manage several projects at once and also have other roles within their business unit or group. An employee can be in charge of three projects, member of two task forces, editor of the magazine, and organizer of the holiday party. A great deal of personal organization is required to manage those roles whose goals, partners, tools and documents are likely to be very different.

\section{Proposed directions}

Our exploration of future work environments led to two main concepts: Organization overviews provide a consistent presentation of the organization and the results of manual or semiautomated searches $[1,2]$. Overviews can be adapted for each class of users to map the multiple personal roles an individual has in an organization. After command line interfaces, graphical user interfaces, and the current "docu-centric" designs, a natural direction is towards a role-centered approach where we believe the emphasis is on the management of those multiple roles. Each role involves coordination with groups of people and accomplishment of tasks within a schedule.

This paper presents a scenario illustrating our proposed interface and then discusses the main elements of the design. 


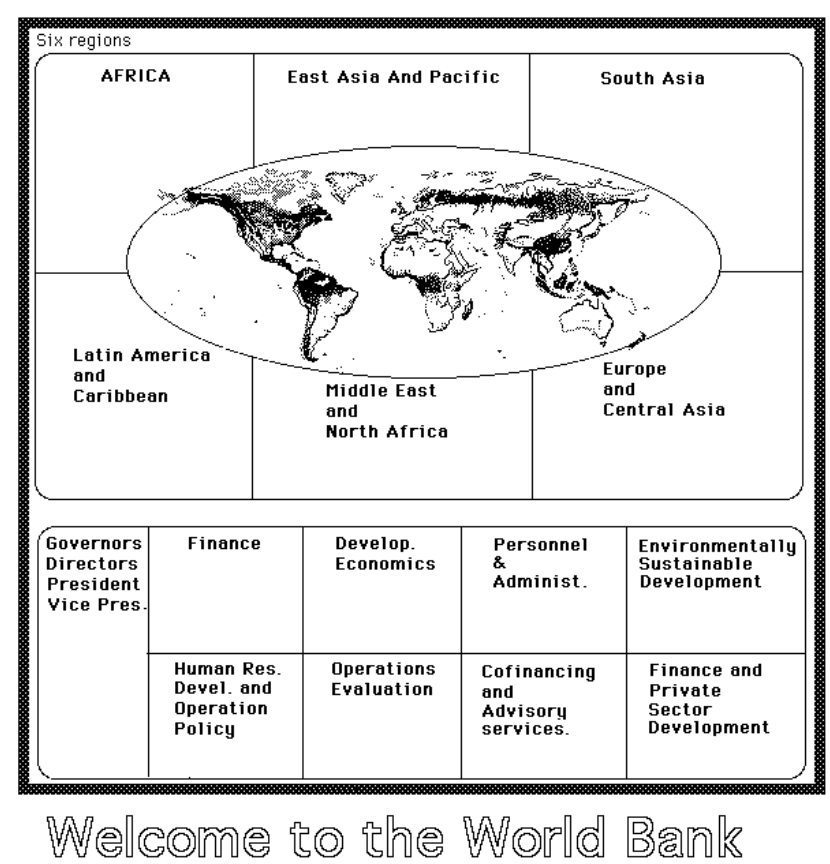

Figure 1. The Bankscape Organizational overview for visitors or newcomers.

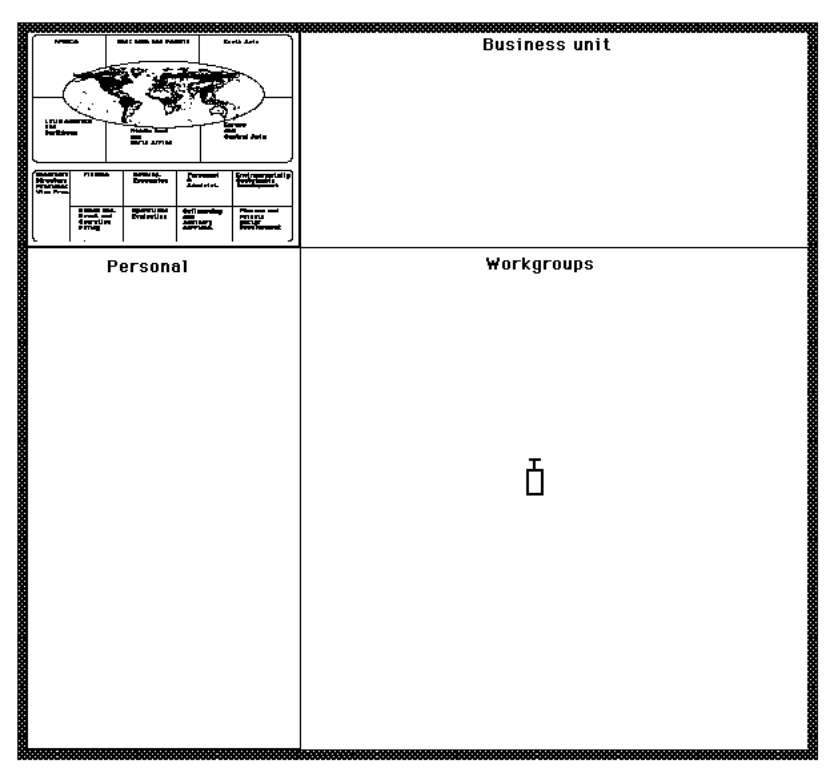

Figure 2b. Depending on the task, the bankscape can be streched to allocate more space to certain areas

\section{Example Scenario}

\subsection{The Bankscape}

When visitors or outsiders access the Bank system via Internet they are presented with a visual overview of the bank, conveying at a glance what the bank is about (Figure 1). The six regions of the bank are shown and, the names of the departments show that finance and economics are major topics. Such an institu-

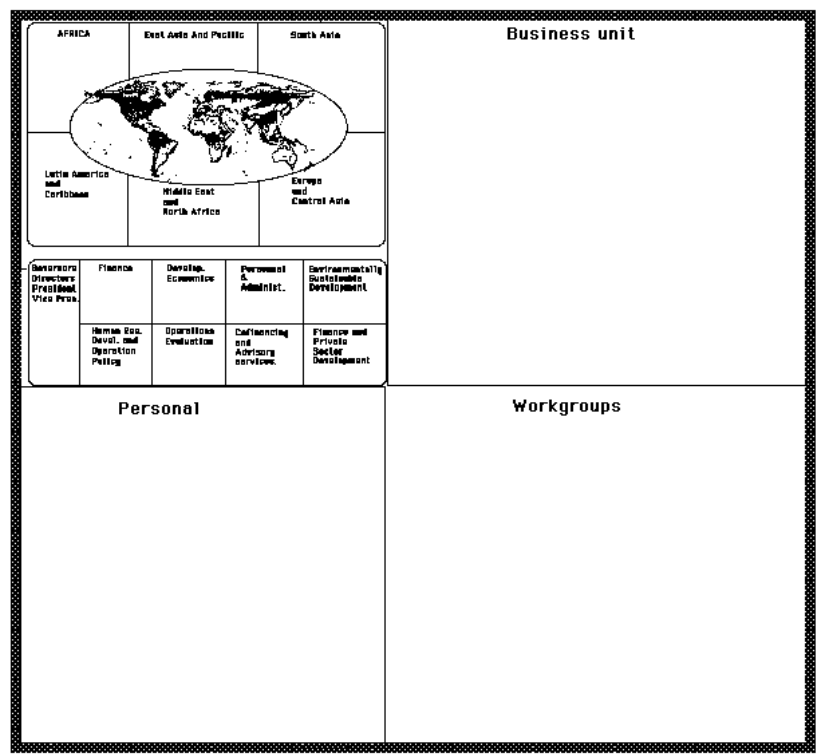

Figure 2a. A personal Bankscape showing the employee's workgroups and business unit

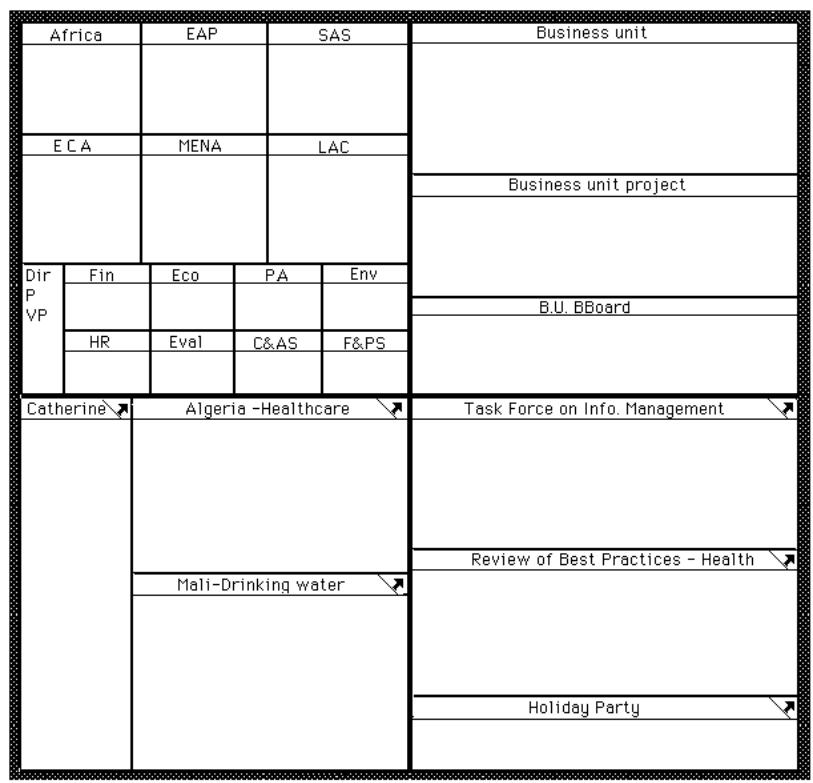

Figure 2c. The Bankscape can show more details as users become experts

tional overview should be informative as well as attractive since for most users it will be their first contact with the Bank.

But employees would also want to see their own workspaces (Figure $2 \mathrm{a}-\mathrm{c}$ ). Therefore their personal Bankscape includes in addition to the institutional area, their personal space, their workgroups and their business unit. To allow users to focus on areas of interest, the size of each area can be changed. A pump tool can be used to inflate areas (Figure 2b) or a hook tool to pull corners (an implementation of such tools was made and is 
described in [3]). For example, to search for a bank policy, users would stretch the institutional area to give more space and see more details while the search is conducted.

As familiarity with the system grows, each area becomes more detailed. Figure $2 \mathrm{c}$ shows the Bankscape for an employee responsible for 2 projects (one in Mali, one in Algeria) and who participates in three group projects (a task force on information management, the collection of best practices on health, and the organization of a party). The name of the task manager's business unit would appear in the top right (with appropriate subdivisions). And finally the task manager can see his or her region (e.g. Africa) in the institutional area. The lower part of the Bankscape corresponds to the user's role(s) at the bank while the upper part represents the environment or community in which the work takes place, the place where information is searched and reports are delivered and archived.

More details could be shown on the Bankscape. Expert users can handle very compact overviews which give rapid access to details even deep in a hierarchy. More details can be given showing the organization of each region or department of the bank. Each role (e.g. the Mali project) can be divided into subroles corresponding to the main steps of the project lifecycle. This tailorable view can then be used consistently over applications to show the results of manual searches or automatic filtering of information.

\subsection{Use of the Bankscape: Example 1 Login view}

After a day of vacation a user sees icons on the Bankscape marking the origin of new emails and the presence of files newly posted by close collaborators [Figure 3]. The M signs corre-

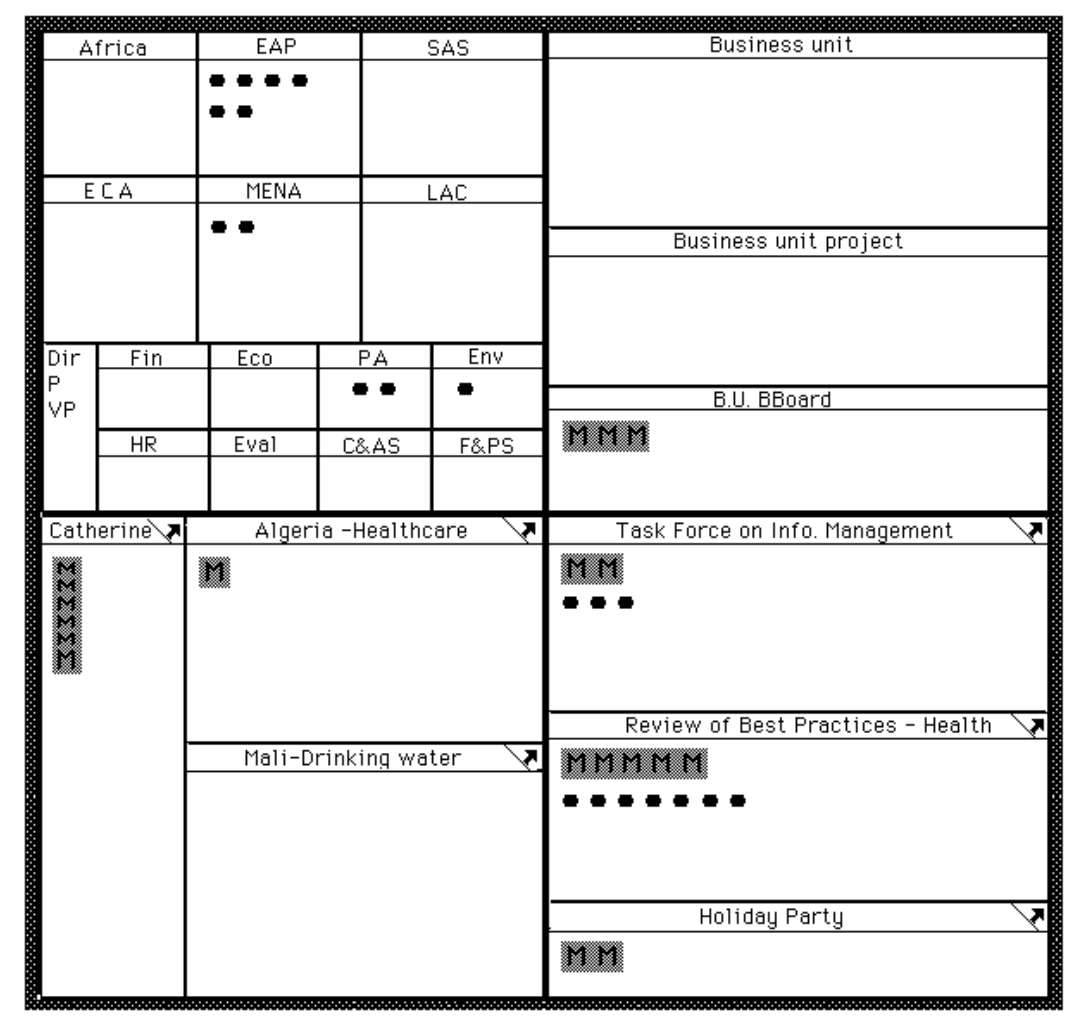

spond to email messages. Their location on the Bankscape gives information on their origin or subject. This can be made possible with semi-structured email [4] whose fields have been filled in by the sender or automatically with some limited text analysis.

At a glance we can see that the "best practice" workgroup was very active. The type of message (meeting setup, report, request for info, etc.) is marked by the shape of the icon and the urgency of message by its color. Selecting one or several mail icons brings the messages to the screen. Other icons (stars) can be new policies or reports prepared by colleagues for review or final publication.

Most likely a traditional calendar and a list of reminders for the day would be displayed along with the Bankscape. The Bankscape makes the organization's activity more visible and facilitates direct access to incoming information.

\subsection{Use of the Bankscape: Example 2 Finding people who worked on similar project}

Paul is working on a new project on health care in Algeria. He wishes to find an economist who has been at the Bank for a long time and who knows about healthcare problems in Algeria.

The top right of the Bankscape lists data sources available: People, Documents and Resources. When the word "People" is dropped on the control panel all the attributes are shown in the control panel and people appear in all parts of the Bankscape (Figure 4).

There are so many people at the bank that only the number of people within each area appears. Paul zooms in on the institutional area to see more details. He filters the people shown on the Bankscape with the control panel. (e.g. he looks only at oldtimer economists who wrote reports on health in Algeria). Paul can also restrict to people who wrote bank reports and specify the type of reports. As the filters are adjusted on the control panel the number of people gets smaller and actual faces of people soon replace the numbers. Within each area the faces are ordered (for example by seniority). At each step the Bankscape reflects the effect of the query (Figure 5).

When the search has been sufficiently narrowed down a single action brings the information about an individual, the list of corresponding reports, and possibly the documents themselves [Figure 6]. The personal information window provides direct connection to send email or automatically dial the telephone number. A click on the "close all info" button closes at once all the windows about a person. This coordinated window management reduces the house-keeping

Figure 3. The Bankscape at login time., showing the new emails and their origin (M's) and newly published files such as policies or group documents $(*)$ 


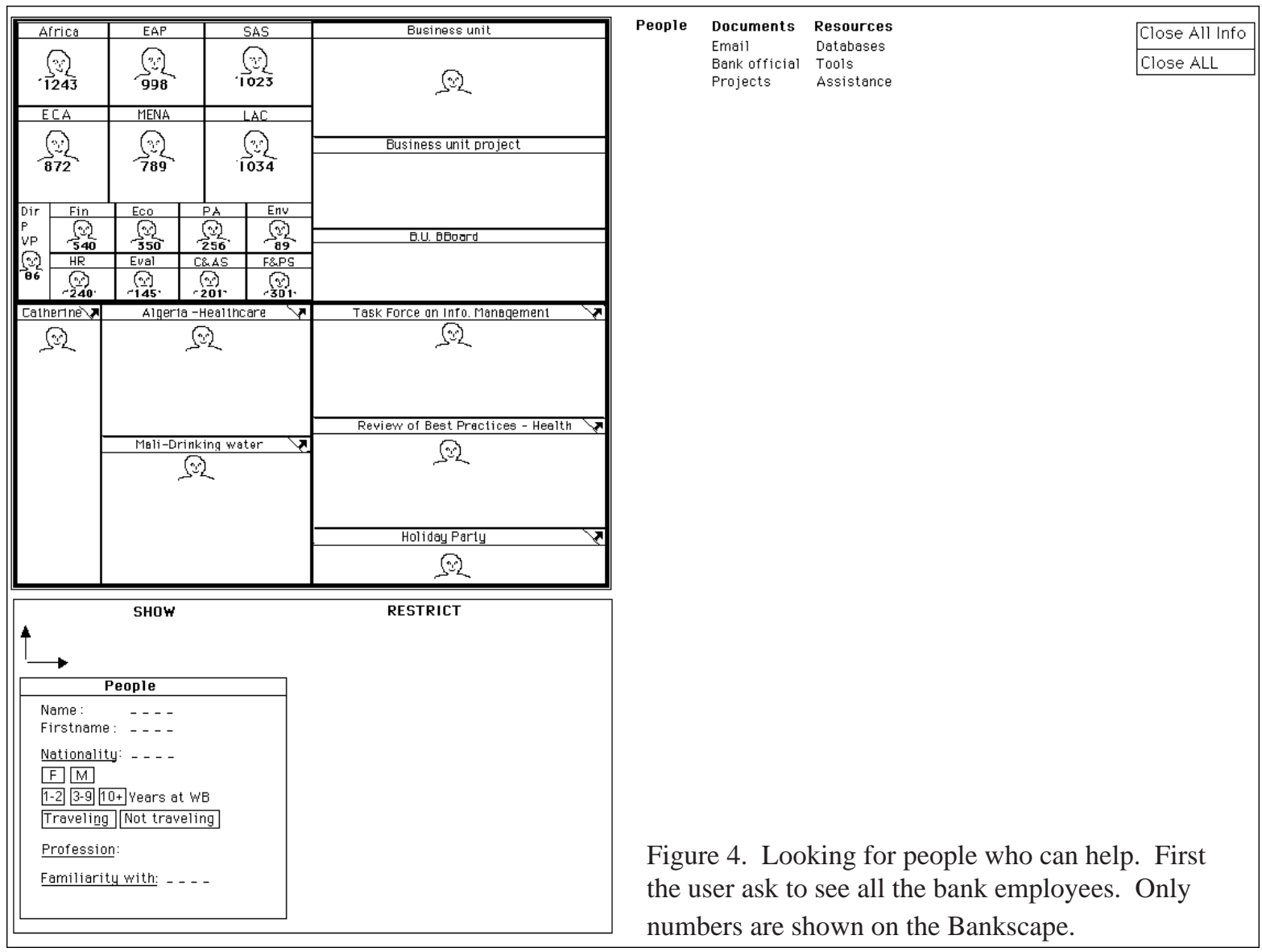

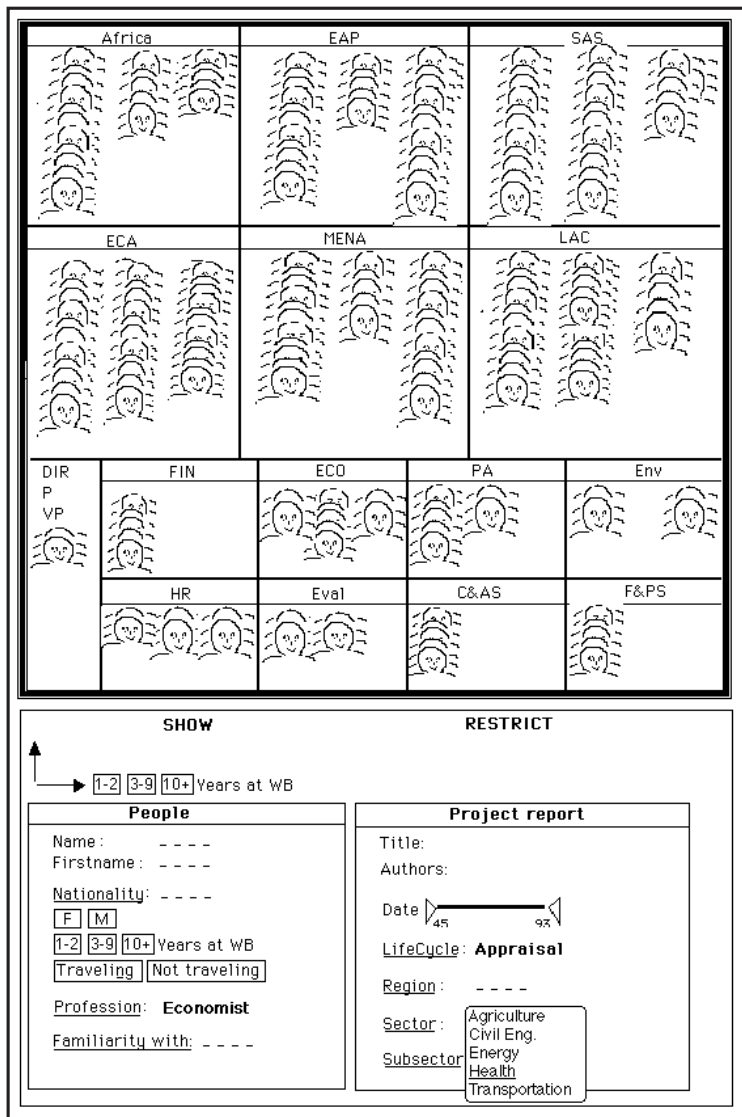

\begin{tabular}{|c|c|c|c|}
\hline \multirow[t]{2}{*}{ People } & \multirow{2}{*}{$\begin{array}{l}\text { Documents } \\
\text { Email } \\
\text { Bank of ficial } \\
\text { Projects }\end{array}$} & \multirow{2}{*}{$\begin{array}{l}\text { Resources } \\
\text { Databases } \\
\text { Tools }\end{array}$} & Close All Info \\
\hline & & & Close ALL \\
\hline
\end{tabular}

Figure 5. The Bankscape has been "zoomed" on the institutional area. Then employees are filtered (e.g. according to their position and the type of reports they have authored.) Faces start to appear on the Bankscape, here ordered by seniority. 


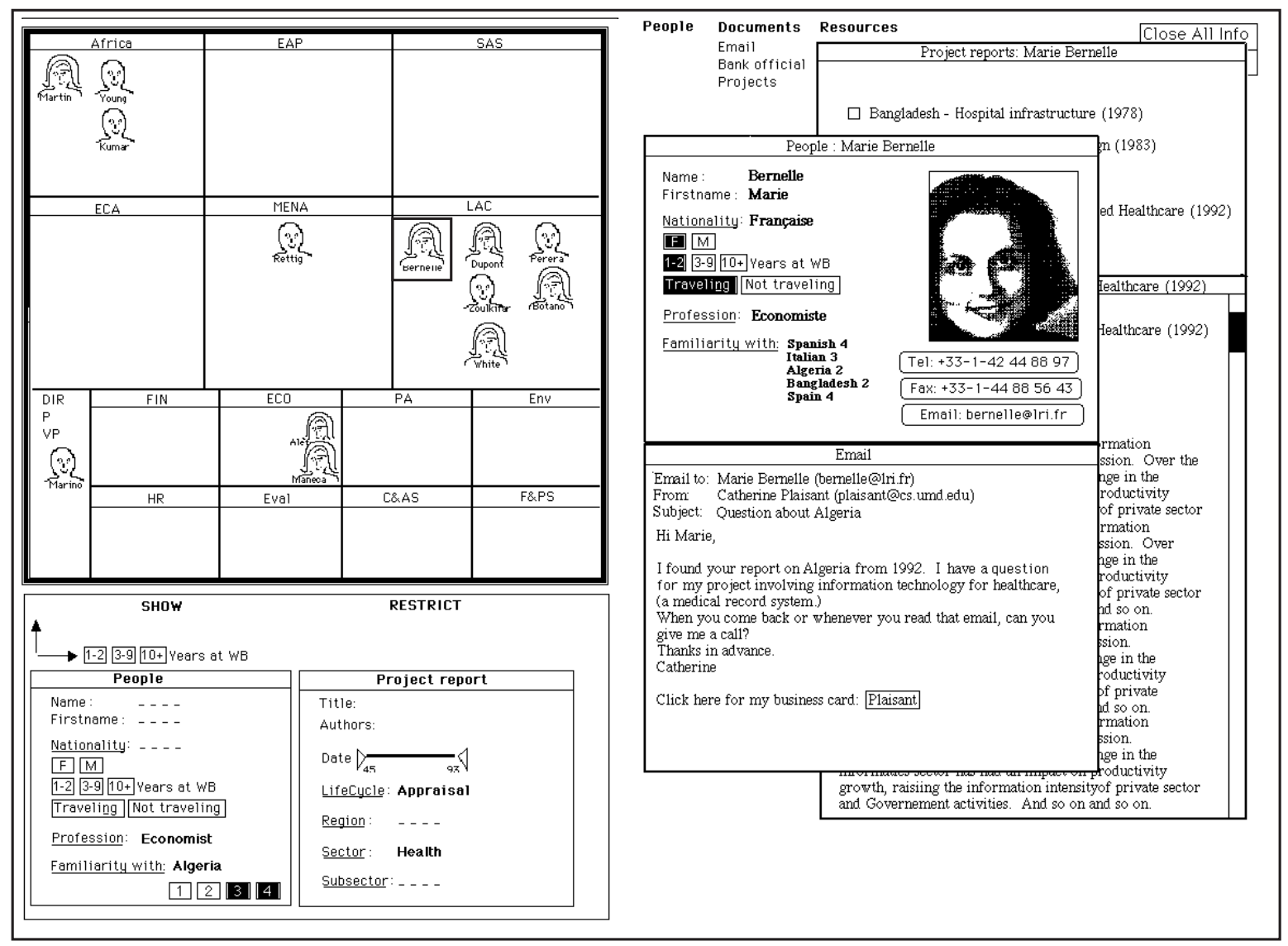

Figure 6: Seeing the effect of each step of the query helps refine the query until a good set of people is found.

Then information about people and document is directly accessible

needed when managing windows individually. Similarly Figure 7 gives another search example where a user asked to display ressources then restrict to resources only on PC, and related to "budget".

\subsection{Gathering information for a role}

When a good set of people has been found the face icons can be moved into the area corresponding to the Algeria project role (Figure 8). The Bankscape provides a consistent support to present results, then results are placed in the appropriate role.

\subsection{Focusing on a role}

By double-clicking on the "Algeria-healthcare" area of the Bankscape users get access to all the information related to the role as project manager for this Algeria project. The Bankscape recedes smoothly in the top left corner and the role fills the screen (Figure 9).

The role shows a vision statement, a task hierarchy, a list of collaborators and other "gathered" people and a schedule on a calendar. People are constantly visible and the pictures act as reminders and as active menus for email, phone, or fax.

Seeing a picture on the screen can act as powerful reminder (people expecting things from you, people who were supposed to deliver something to you, etc.). The schedule appears focused on that specific role and of course only the relevant files and tools are shown. The role can be focused on a task, which in turn filters the schedule, people, and files accordingly. Unifying the schedule to reflect all the roles allows checking for possible scheduling conflicts.

The Bankscape is still visible on the top left corner of the screen. Even if small, each area can be seen and selected. When receiving a call relevant to another role, shifting to that role environment can be done with a single selection. The personal role management directs efforts toward the stated vision. The vision button is always accessible as a reminder.

\section{Personal role management}

A great deal of personal organization is required to manage these roles whose goals, partners, tools and documents are likely to be very different. The previous research on role theory $[5,6]$ or Computer Supported Collaborative Work [7] focuses mainly on the coordination of individuals while our goal is to assist individuals manage their multiple roles.

We propose Personal Role Management as the guiding concept for the next generation of graphic user interfaces [1]. The first generation was the command line interfaces that required users to know about computer concepts and syntax; These were replaced by second generation graphical user interfaces with the desktop metaphor, icons, and folders. Now, the third 


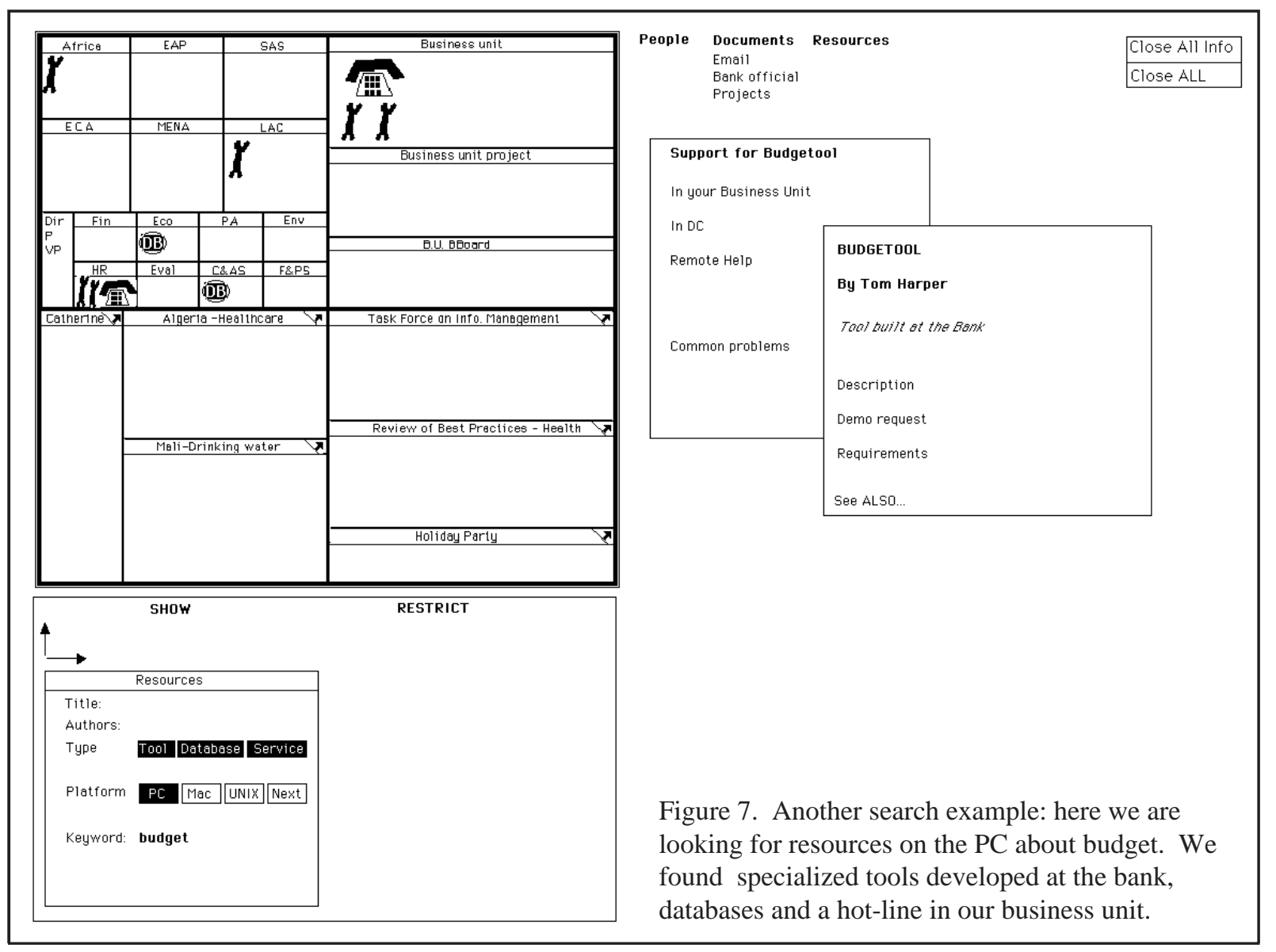

generation emphasizes a docu-centric approach, in which applications fade into the background while multimedia documents become the center of attention. Our proposed fourth generation user-centered design emphasizes user's roles, colleagues, and tasks rather than documents. Each separate role involves coordination with different groups of people and accomplishment of tasks within a schedule.

\section{Organization overviews}

Our work on visual information seeking has highlighted the importance of overviews to facilitate orientation, monitoring, and detection of clusters, outliers, or trends. For the desktop we suggest the use of a tailorable overview of the organization (here called Bankscape). It reflects the organization of the tools and information which can be explored. This overview, coupled with display controls and query controls, provides a consistent visual support to display the result of searches [8]. The Bankscape overview is also a part of the Personal Role Management. It provides a visual representation of the relationships between a user's many roles. This representation can be used to access the roles themselves or to gather documents, people or resources for a role.

\section{Dynamic queries}

Dynamic queries [9] are a novel approach to information seeking that may enable users to cope with information overload. They allow users to see an overview of the database, rapidly (100 msec updates) explore and conveniently filter out unwanted information. The use of dynamic queries allows users to rapidly get to a usable subset of names. Users can readjust the query while watching the Bankscape to see how the result is affected by each step of the query. In comparison a traditional boolean search does not give any feedback until the final query is analyzed and the final result returned. This makes it difficult to modify the query to broaden or narrow the search because users do not know what to change in the query.

\section{Interconnected applications}

Future desktop environments will allow users to make seamless connections between the different sources of information . The prototype illustrates how users can potentially move easily between searching for people, reading documents or information, and initiating communication with colleagues. Names and numbers do not need to be retyped or copied. Default behavior or preference settings take in to account previous actions in other applications.

\section{Coordinated window management}

A careful analysis of users' tasks should allow the design of coordinated window applications in which the windows open- 


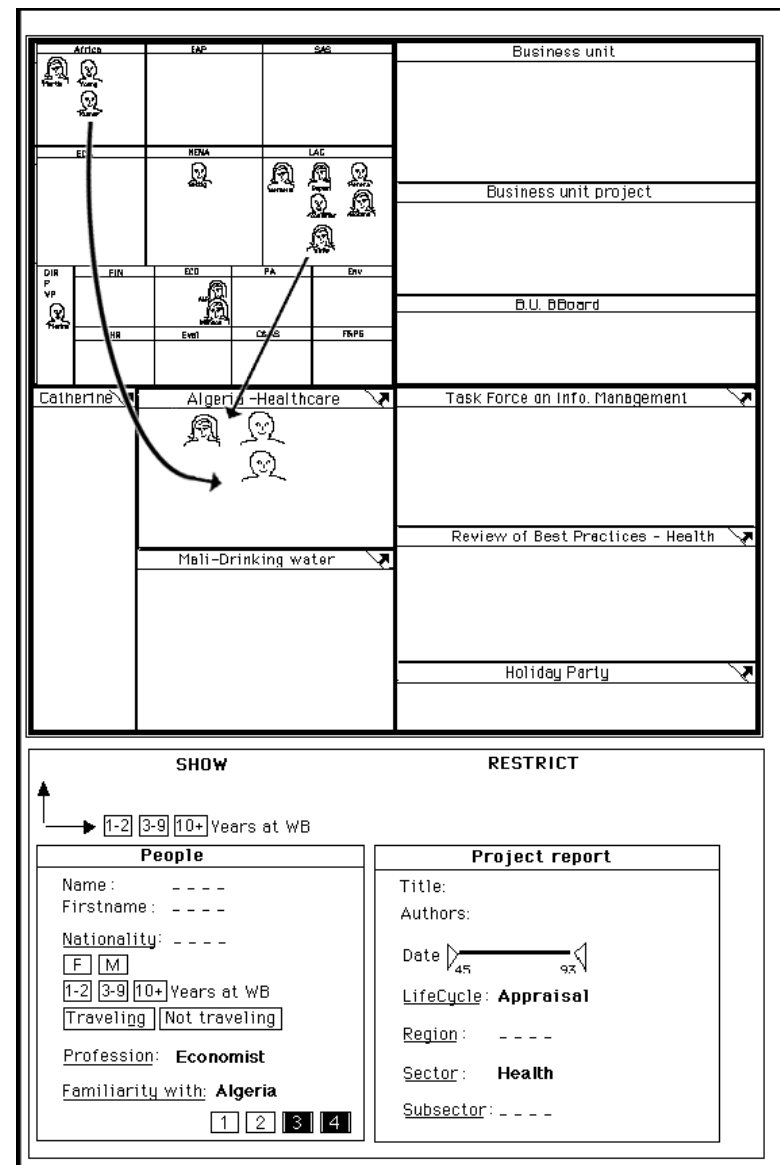

ing, closing and resizing can be done semi-automatically as a result of the user's activity in the task domain $[10,11,12]$. For example synchronized scrolling will assist the user in comparing files. The prototype gives an example of coordinated window management when related windows are closed together (putting away all the information about a person). Such techniques will relieve the user from much of the tedious window house-keeping that plagues current window applications. The Personal Role Manager is also a powerful example of automated window management as all windows pertinent to a role are opened, sized and loaded specifically for each role.

\section{Large displays}

Screen size and resolution have been consistently increasing with each new hardware generation and we believe that this trend will continue and that larger screen will be more available to users in the coming years as prices decrease. There is not yet an empirical study showing quantitative benefits for larger screens. On the other hand it has been shown that display rate has an influence on productivity [9] because time is lost waiting for the screen to refresh and that users of window environments spend a very significant percentage of time scrolling, resizing and moving windows [10]. Multiple screens were also found to be helpful, and we see in our own work environment that users always prefer using the larger screens when available. We believe that larger screens reduce the need for constant window
Figure 8. After finding the information needed (e.g. the people who might be able to help) icons are moved to the role. The Bankscape has been zoomed out to show the roles again.

manipulation and make many tasks (e.g. editing, proofing, comparing or merging documents) faster and less error prone.

\section{Conclusions}

Our prototype has helped us refine the proposed organizational overviews and personal role manager concepts. We have begun implementation of screen management tools to explore alternatives for coordinated window management, and are working on a usable implementation in commercially viable software environments. Breaking away from the currently popular cluttered desktops of the Macintosh, Windows, and Motif is difficult but the capacity to cope with more complex tasks is appealing. We have many steps to go before an empirical test with users can be attempted, but the new ideas spawned by this research are encouraging.

\section{Acknowledgments}

We greatly appreciate the assistance of Michael Sharpston for guiding our work and the financial support of the World Bank. This material is based upon work supported by the National Science Foundation under Grant No. NSF EEC 94-02384.

\section{References}

[1] Shneiderman, B., and Plaisant, C.(1994), The Future of Graphic User Interfaces: Personal Role Managers, Keynote address, in People and Computers IX, British Computer Soci- 


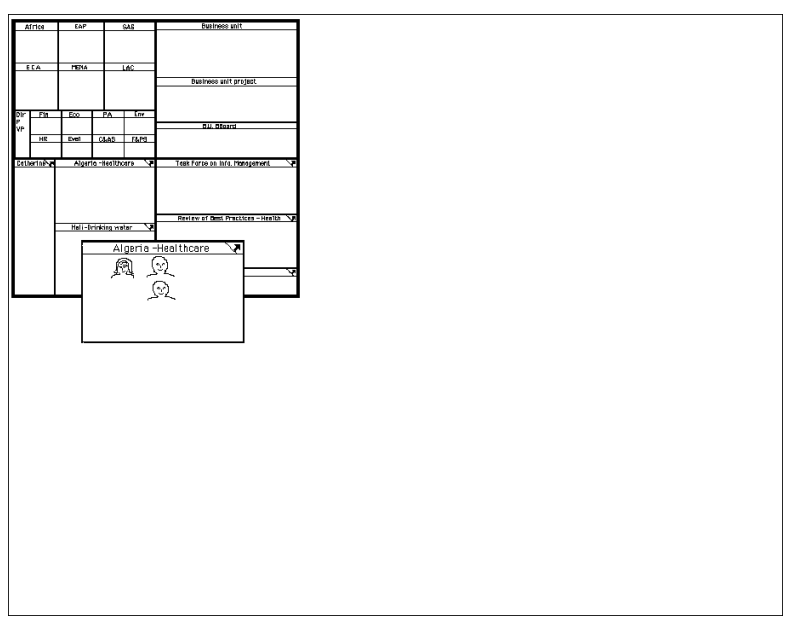

9.a

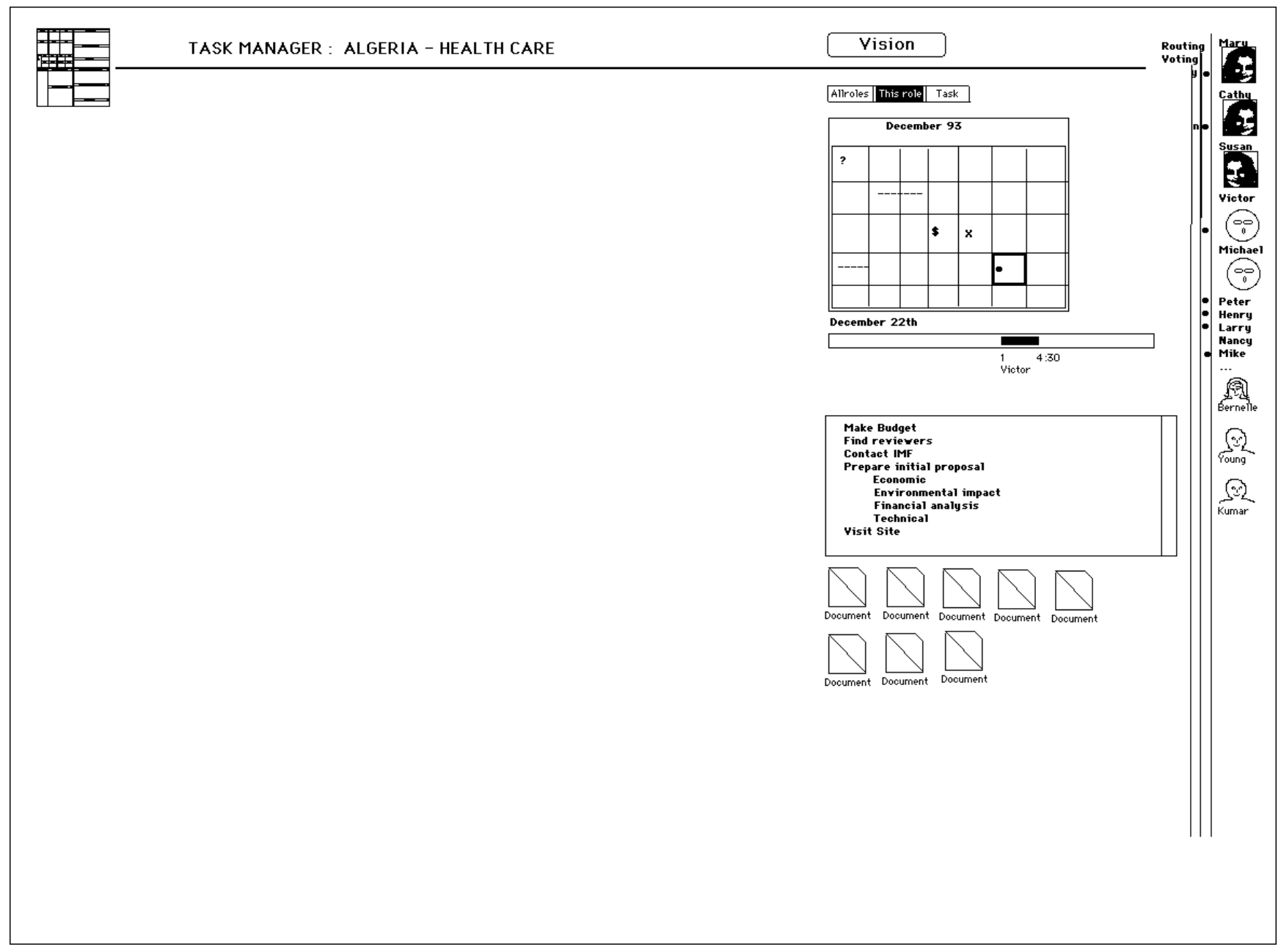

Figure 9. When the Healthcare in Algeria project management role is opened the Bankscape recedes (9.a) and the role fills the screen (9.b and 9.c) I can see the schedule, list of tasks, colleagues and the three people I just found. There is still a lot of space for other work windows. And the small bankscape allows me to change role in one single click. 
ety HCI'94, Cambridge University Press (August 1994), 3-8.

[2] Plaisant, C. and Shneiderman, B., (1995), Organization overviews and role management: Inspiration for future desktop environments, CHI' 95 Technical Program Video, ACM, New York. Also available in the HCIL Video report 1994, University of Maryland, College Park MD.

[3] Asahi, T., Turo, D., and Shneiderman, B. (1995), Using treemaps to visualize the analytic hierarchy process, To appear Information Systems Research. [demo also available in CHI '95 and HCIL 94 videos]

[4] Malone, T. (1983), How do people organize their desks? Implications for the design of office information systems, $A C M$ Trans. on Office Information Systems 1, 1, 99-112.

[5] Biddle, B. J. and Thomas, E. J. (1979), Role Theory: Concepts and Research, Krieger Publishing.

[6] Roos, L. L. Jr. and Starke, F. A. (1981), Organizational roles, in Nystrom, P. C. and Starbuck, W. H. (Editors), Handbook of Organizational Design, Vol. 1: Adapting Organizations to Their Environments, Oxford University Press.
[7] Singh, B. and Rein, G. (1992) Role Interaction Nets (RINS): A Process Description Formalism, MCC, Austin, TX, USA, Technical Report CT-083-92

[8] Plaisant, C., Carr, D., and Shneiderman, B. (1995), Image browsers taxonomy and design guidelines, IEEE Software 12, 2 (March 1995), 21-32.

[9] Shneiderman, B. (1994), Dynamic queries for visual information seeking, IEEE Software 11, 6 (November 1994), 70-77

[10] Davies, S., Bury , K. and Darnell, M. An experimental comparison of windowed vs. non windowed operating system environment. Proc. of the Human-Factors Society 29th Annual Meeting, 250-254

[11] Norman, K. L., Weldon, L. J., and Shneiderman, B. (1986), Cognitive layouts of windows and multiple screens for user interfaces, International Journal of Man-Machine Studies 25, , 229-248.

[12] Henderson, A. and Card, S. K. (1986), Rooms: The use of multiple virtual workspaces to reduce space contention in a window-based graphical user interface, ACM Trans. on Graphics 5, 3, 211-243. 